\title{
ANALISIS KEPUASAN PELANGGAN TERHADAP HASIL KINERJA BENGKEL NADER JAYA MOTOR DENGAN MENGGUNAKAN METODE IMPORTANCE PERFORMANCE ANALYSIS DAN CUSTOMER SATISFACTION INDEX
}

\author{
Akhmad Izzuddin ${ }^{1}$, Deny Andesta ${ }^{2}$, Moh Jufriyanto ${ }^{3}$ \\ Program Studi Teknik Industri, Fakultas Teknik, Universitas Muhammadiyah Gresik \\ Jl. Sumatera 101 GKB, Gresik 61121, Indonesia \\ e-mail: akhmadizzuddin4@gmail.com
}

\begin{abstract}
ABSTRAK
Sepeda motor merupakan alat transportasi yang sangat penting dalam kegiatan aktivitas manusia setiap harinya. seiring berjalanya waktu dan perkembangan zaman motor bukanlah suatu barang yang mewah atau sulit dicari dizaman sekarang. Tujuan Penelitian untuk mengetahui tingkat kepuasan pelanggan terhadap atribut/komponen pelayanan dari bengkel dan mengetahui kualitas atribut/komponen pelayanan apa sajakah yang dianggap penting dalam menentukan kepuasan pelanggan dibengkel.penelitian ini merupakan jenis data primer yang diperoleh atau dikumpulkan langsung dilapangan oleh orang yang melakukan penelitian atau yang bersangkutan memerlukannya. Hasil Penelitian uji validitas nilai hasil dari pengujian yang didapat kan nilai $\mathrm{r}_{\text {hitung }}$ lebih besar dari pada nilai $r_{\text {tabel }}$ untuk semua atribut. sedangakan uji rehabilitas nilai dari cronbach's alpa yang didapatkan yaitu 0,936 untuk kinerja dan0,884 untuk nilai harapan. nilai kedua cronbach's alpa dinyatakan reliable karena kedua nilai koefisien reliabilitas $\geq 0,6$. nilai customer saticfaction index(csi) sebesar $69,445 \%$ berarti masih ada 30,55\% konsumen yang belum mampu dipuaskan sepenuhnya oleh bengkel. meskipun pihak diindikasikan dengan nilai csi mendekati angka100\% itu jauh lebih baik. Kesimpulan nilai tingkat kepuasan pelanggan terhadap pelayanan bengkel nader jaya motor adalah $69,445 \%$ artinya pelanggan merasa "puas" atas kinerja pelayanan. peningkatan kualitas pelayanan bengkel lebih optimal harus segera memperbaiki pada atribut kuadaran 1 seperti bengkel bertanggung jawab penuh hasil servis, kualitas servis yang diberikan bengkel, adanya penjelasan informasi tentang kualitas suku cadang asli/tidak, kebersihan kenyamanan fasilitas-fasilitas yang diberikan oleh bengkel, area parkir yang luas dan bersih, kelengkapan peralatan begkel,ketepatan waktu saat pengerjaan service dengan waktu selesai pengerjaan yang diberikan mekanik, jam kerja bengkel, kelengkapan sparepart.
\end{abstract}

Kata Kunci : Importance Performance Analysis, Customer Saticfaction Index (CSI), Bengkel Nader Jaya Motor

\begin{abstract}
Motorcycles are a very important means of transportation in human activities every day. over time and the development of the era of the motor is not a luxury item or difficult to find in this day and age. The purpose of the study was to determine the level of customer satisfaction with service attributes/components from the workshop and to find out what quality attributes/service components were considered important in determining customer satisfaction at the workshop. concerned need it. Research results test the validity of the results of the test obtained, the value of rcount is greater than the value of rtable for all attributes. while the rehabilitation test value of Cronbach's negligence obtained is 0.936 for performance and 0.884 for expected value. the second value of cronbach's omission is declared reliable because both values of the reliability coefficient are $\geq 0.6$. The customer satisfaction index (CSI) value of $69.445 \%$ means that there are still $30.55 \%$ of consumers who have not been able to be fully satisfied by the workshop. although the party indicated with a csi value close to $100 \%$ it is much better. In conclusion, the value of the level of customer satisfaction with the service of the Nader Jaya Motor workshop is $69.445 \%$, meaning that the customer feels "satisfied" with the service performance. improving the quality of workshop services more optimally must immediately improve on quadrant 1 attributes such as the workshop being fully responsible for the results of the service, the quality of the services provided by the workshop, an explanation of information about the quality of genuine spare parts / not, cleanliness and comfort of the facilities provided by the workshop, parking area spacious and clean, completeness of workshop equipment, punctuality when working on the service with the completion time given by the mechanic, workshop hours, completeness of spare parts.
\end{abstract}

Keywords: Importance Performance Analysis, Customer Saticfaction Index (CSI), Nader Jaya Motor Workshop 


\section{Jejak Artikel}

Upload artikel : 1 Desember 2021

Revisi : 15 Desember 2021

Publish : 31 Januari 2022

\section{PENDAHULUAN}

Sepeda motor merupakan alat transportasi yang sangat penting dalam kegiatan aktivitas manusia setiap harinya. Menurut Santiana (2018), seiring berjalanya waktu dan perkembangan zaman motor bukanlah suatu barang yang mewah atau sulit dicari dizaman sekarang. Oleh karena itu dibutuhkan suatu perbaikan secara rutin di bengkel agar kendaraan pada saat digunakan bisa berjalan dengan aman dan nyaman. Menurut Sestiayunda (2017),semakin banyaknya jumlah produksi motor yang ada di zaman sekarang maka semakin banyak pula bengkel tempat service dan persaingan yang semakin ketat menentukan masa depan bengkel tersebut. Menurut AISI (Asosiasi industri sepeda motor) distribusi sepeda motor di tahun 2021 perbulanya jumlahnya berbeda-beda bisa dilihat berdasarkan data berikut :

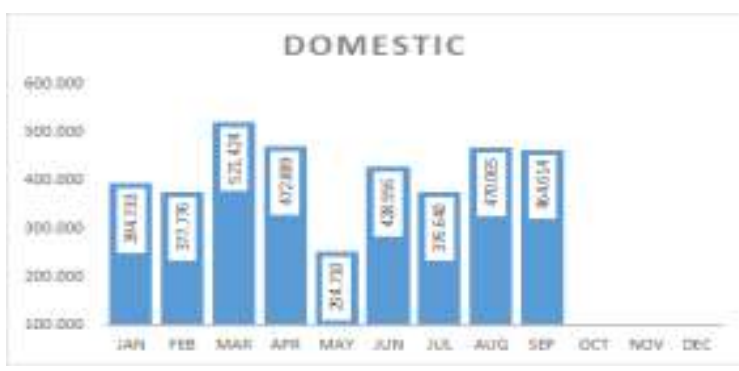

Gambar 1. 1Diagram Data Distribusi

Sepeda Motor Domestic

\section{EXPORT}

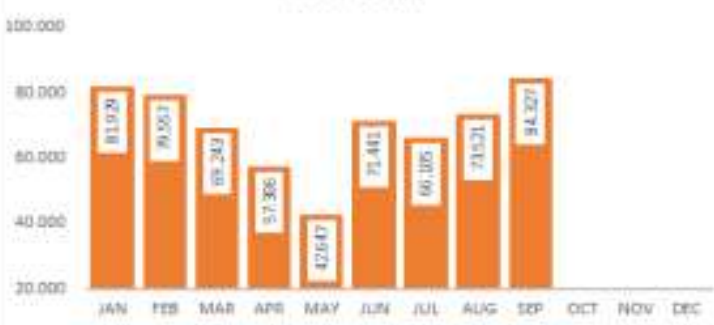

Gambar 1. 2 Diagram Data Distribusi Sepeda

\section{Motor Export}

Berdasarkan gambar diagram dosmestik diatas rata-rata dari bulan Januari sampai September berjumlah 3,761,407 dan untuk Export 626,076 berbagai macam cara digunakan untuk dapat membuat pelanggan tersebut puas akan pelayanan yang diberikan sehingga pengguna jasa bisa kembali lagi untuk melakukan perbaikan di bengkel tersebut.

Oleh karena itu, pihak bengkel harus mengambil inisiatif untuk lebih memperhatikan kebutuhan pelangganadapun upaya yang digunakanya yaitu dengan memberikan garansi 1 minggu setelah menservis kendaraanya supaya membuat pealanggan puas dan diperlukan suatu konsep berwawasan konsumen dimana bengkel memusatkan perhatian penuh terhadap kebutuhan dan keinginan konsumen. Kepuasan konsumen adalah evaluasi ketidak sesuaian atau yang dirasakan antara harapan sebelumnya dengan kinerja yang dirasakan setelah pemakaiannya.

Pada penelitian ini penulis menggunakan 
metode kualitas pelayanan dengan pengukurannya menggunakan Importance Performance Analysis (IPA) dan Customer Satisfaction Index (CSI) dimana metode kualitas pelayanan berfungsi sebagai parameter kesenjangan (gap) misalnya nilai kepuasan yang tidak seiring dengan nilai kepentingan yang diharapkan konsumen tidak terpenuhi terhadap pelayanan yang diberikan oleh bengkel NADER JAYA MOTOR. Selanjutnya output dari kualitas pelayanan akan disaring untuk digunakan sebagai input dari Importance Performance Analysis (IPA) dalam diagram kartesius yang bertujuan untuk memperjelas apa saja atribut yang bisa dijadikan prioritas. Sehingga atribut apa saja yang seharusnya dibutuhkan dan ditingkatkan terkait dengan kualitas pelayanan, sedangkan Customer Satisfaction Index (CSI) digunakan sebagai acuan untuk menentukan sasaransasaran yang relevan dapat diraih oleh bengkel motor di masa mendatang.

\section{METODOLOGI PENELITIAN}

Penelitian ini adalah jenis data primer. Data primer adalah data yang diperoleh atau dikumpulkan langsung dilapangan oleh orang yang melakukan penelitian atau yang bersangkutan yang memerlukannya. Jenis data primer yang digunakan dalam penelitian ini adalah berupa kuesioner yang diberikan kepada pelanggan bengkel NADER JAYA MOTOR. Adapun data sekunder yang digunakan dalam penelitian ini adalah untuk memperkuat landasan teori dan sebagai rujukan dalam mempelajari penelitian yang telah dilakukan sebelumnya.
Penelitian ini dilakukan di Desa Watuagung, Bungah,Gresik Penentuan daerah penelitian ditentukan secara purposive sampling dengan pertimbangan lokasi penelitian Waktu penelitian ini dilakukan mulai dari bulan juni dan juli 2021.

Gambaran dari Flow chart metodologi penelitian penelitian yang ditunjukkan dibawah ini:

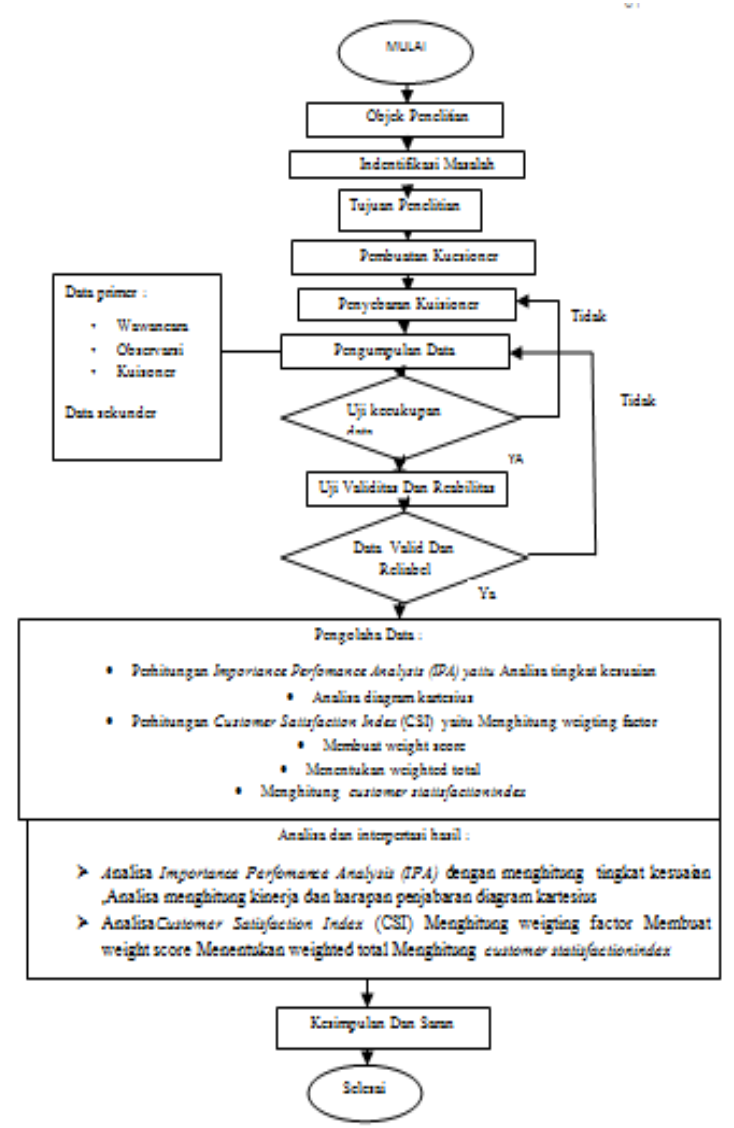

Gambar 3. 1 Flow Chart Metode Penelitian

Pada penelitian selanjutnya Parasuraman et.,al (1988) menyempurnakan dimensi tersebut kemudian diolah lagi sehingga akhirnya disederhanakan menjadi 5 dimensi yaitu:

1.Bukti langsung (tangibles); meliputi fasilitas fisik, perlengkapan, pegawai. 
2.Keandalan (reliability); yakni kemampuan memberikan pelayanan yang dijanjikan dengan segera, akurat, dan memuaskan.

3.Daya tanggap (responsiveness) yaitu keinginan para staf untuk membantu para pelanggan dan memberikan pelayanan dengan tanggap.

5. Jaminan (assurance); mencakup pengetahuan, kemampuan, kesopanan, dan kepercayaan

6. Empati (empathy); meliputi kemudahan dalam melakukan hubungan, komunikasi yang baik,

Disini saya melakukan penyebaran kuisoner awal dan melakuakan wawancara untuk mendapatkan atribut yang seuai dari pelanggan dalam atribut yang di proleh dari pelangan dibedakan menjadi 5 dimensi atribut yaitu tangibles, reability, responsive, assurance, empaty. Adapun buktinya bisa dilihat pada lampiran penilitian kualitas pelayanan bengkel NADER JAYA MOTOR atribut yang di peroleh seperti tabel di bawah ini :

Tabel 3. 1 Atribut Kualitas Pelayanan Bengkel Nader Jaya Motor

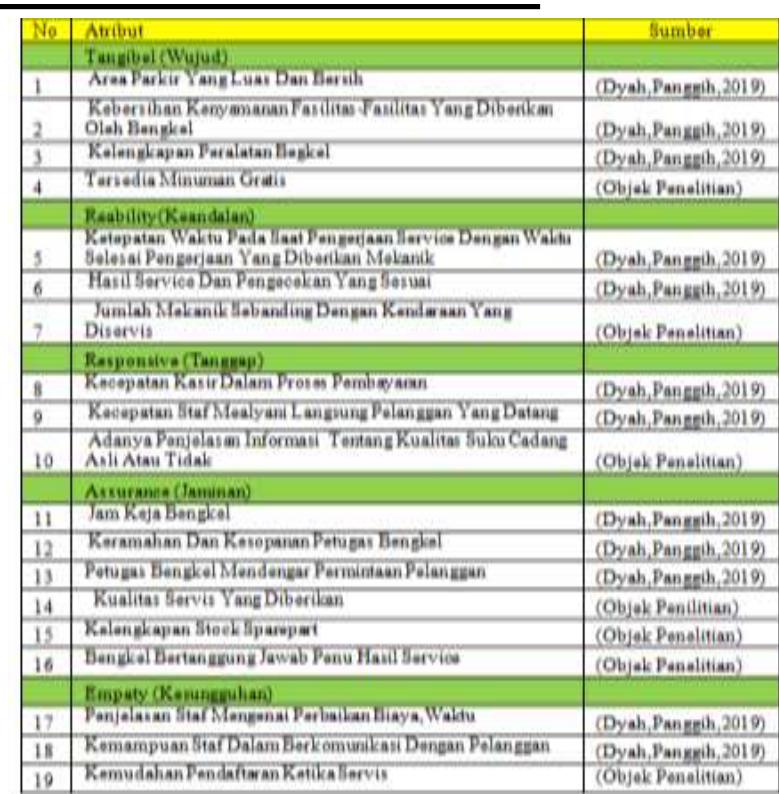

Setelah atribut terkumpul dan dibedakan menjadi 5 dimensi dari pelanggan. selanjutnya dilakukan pengambilan sempel yaitu dengan membagikan kuisioner ke pelanggan dalam kuisoner ada 2 dimensi yaitu menggunakan tingkat kepentingan dan kepuasan.Pada tahap ini dilakukan pengolahan terhadap data data yang telah dikumpulkan,adapun pengolahan data dilakukan untuk mengetahui tingkat kepuasan pelanggan terhadap kinerja bengkel NADER JAYA MOTOR berdasarkan faktor-faktor yang mempengaruhi konsumen menggunakan metode Customer Satisfaction Index (CSI) dan Metode Importance Performance Analysis (IPA) digunakan untuk Untuk mengetahui hal-hal yang menjadi prioritas perbaikan tehadap faktor- faktor yang mempengaruhi tingkat kepuasan konsumen pada bengkel motor.

Penyebaran dilakukan ke pelanggan Bengkel Nader jaya Motor. Pada Tahap ini dilakukan pengumpulan data yang digunakan untuk mendukung dan memcahkan permasalahan yang ada. Dalam pengumpulan data ada 2 data yang diperlukan adapun data-data yang diperlukan yaitu : 


\section{A. Data Primer}

Data asli yang diproleh langsung dari objek penelitian ini untuk menjawab masalah penelitian secara khusus yang dikumpulkan dengan cara :

1. Wawancara yaitu melakukan komunikasi dengan pihak bengkel untuk memproleh informasi yang diperlukan.

2. Observarsi yaitu untuk mengamati secara langsung bagaimana kualitas pelayanan di bengkel NADER JAYA MOTOR

3. Kuisoner yaitu metode pengumpulan data dengan mengajukan pertanyan kepada responden melalui jumlah daftar pertamnyaan guna mengumpulkan informasi mengenai masalah yang sedang diteliti.

\section{B. Sekunder}

Data sekunder yaitu data yang didapatkan dengan mempelajari literaturyang berhubungan dengan penelitian dan dokumen-dokumen bengekel. Data-data ini berisi tentang petunjuk dalam pelaksanaan penelitian dan semua informasi yang bergunadalam penyusunan laporan.

\section{HASIL DAN PEMBAHASAN Analisis Validitas}

Uji validitas dilakukan bertujuan untuk mengetahui bahwa setiap pertanyaan yang di ajukan kepada responden teal dinyatakan valid atau tidak. Pada perhitungan uji validitas menggunakan program aplikasi SPSS versi 25 dengan melihat nilai dari Correcteditem-Total Correlation, hasil dari pengujian yang didapatkan nilai $\mathrm{r}_{\text {hitung }}$ lebih besar dari pada nilai $r_{\text {tabel }}$ untuk semua atribut. Misalnya contoh pada atribut 1 pada data harapan nilai $\mathrm{r}_{\text {hitung }} 0.706$ lebih besar dari nilai $r_{\text {tabel }}$ sehingga atributatribut yang terdapat pada kuesioner semuanya telah dinyatakan valid atau sah dan kuesioner tersebut dapat digunakan untuk tahap pegujian selanjutnya.

\section{Analisis Rehabilitas}

Pada uji rehabilitas dilakukan menggunakan bantuan program aplikasi SPSS versi 25 dengan melihat nilai dari Cronbach's Alpa yang didapatkan yaitu 0,936 untuk kinerja dan 0,884 untuk nilai harapan. Nilai kedua Cronbach's Alpa dinyatakan reliable karena kedua nilai koefisien reliabilitas $\geq 0,6$. Dan bisa dipakai untuk pengujian dengan metode Importance and Performance Analysis (IPA) dan Customer Satisfaction Index (CSI).

\section{Analisis Importance And Performance Analysis (IPA)}

Bedasarkan hasil penelitian analisis metode importance and performance analyisis (IPA) membahas mengenai pemetaan dari nilai kinerja (x) dan harapan (y),dari hasil tersebut maka akan tebentuk matriks yang tediri dari empat buah kuadran yang masing-masing kuadran menggambarkan skala prioritas dalam mengambil kebijakan baik berupa peningkatan kinerja atau mempertahankan kinerja bengkel.

Diagram kartesius menunjukan bahwa ada 7 atribut pada kuadran I berisi atribut-atibut yang memiliki perhatian lebih atau harus diperbaiki, pada kuadran II ada 7 atribut yang harus dipertahankan kinerjanya dan kuadran III ada 1 atribut tingkat memiliki tingkat kepetinganya 
kurang penting dan kurang memuaskan bagi pelanggan, sedangakan kaudran IV memiliki tingkat harapan yang rendah namun tingkat kinerja yang tinggi dapat dilihat diagram di bawah ini :

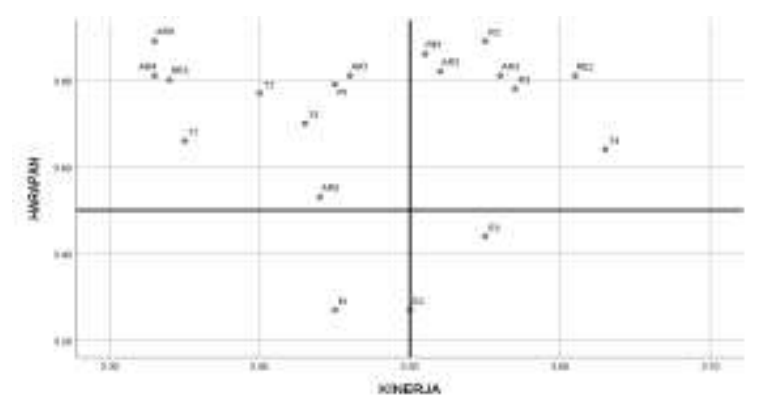

Gambar 5. 1 Diagram Kartesius IPA

\section{Kuadran I}

Kuadran I adalah Prioritas Utama dimana atribut-atribut yang di plotting ke dalam kuadran ini harus mendapatkan perhatian lebih atau harus diperbaiki. Hal tersebut menunjukkan bahwa pelanggan merasakan ketidakpuasan terhadap atribut atau dimensi layanan yang telah diberikan, sehingga perlu adanya perbaikan pada atribut tersebut perlu diprioritaskan. Atributatribut tersebut antara lain atribut pertanyaan AR6, atribut AR4, atribut RE3, atribut T2,atribut $\quad \mathrm{T} 3$,atribut $\mathrm{T} 1$ dan atribut R1,AR1,AR5. Karena atribut tersebut dianggap sangat mempengaruhi kepuasan pelanggan karena menunjukkan unsur jasa pokok namun dari pihak Bengkel Nader Jaya Motor belum melaksanakan sesuai kinerja dari para pelanggan, sehingga pelanggan kecewa/kurang puas. Sebaiknya dari pihak bengkel nader jaya motor secepatnya melakukan perbaikan pada atributatribut pada kuadran ini supaya Pelanggan Bengkel Nader Jaya Motor bisa merasa puas dan mengurangi rasa kecewa daripelanggan.

\begin{tabular}{|c|c|c|}
\hline CUACRALI & ATREUT & DMENSI \\
\hline 2es & 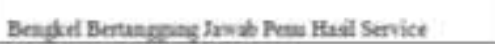 & ASsURANCF \\
\hline 204 & Kavinas Sevis Yo DEeribs & ASSUWWVA \\
\hline REJ & 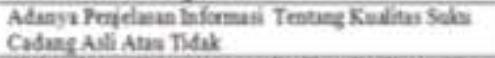 & Raseonesme \\
\hline $\mathbf{n}$ & 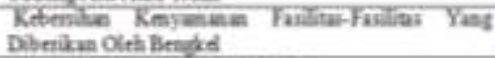 & Tanoraen \\
\hline $\mathbf{n}$ & Asea halir Yang Leas De Berah & Tasoint \\
\hline $\mathbf{n}$ & Kelectapun Fenlutin Bepar & TaNGieel \\
\hline as & 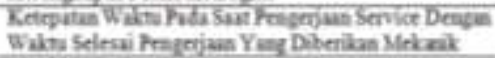 & ReaAury \\
\hline AMI & $\mathrm{I}=\mathrm{K}$ ra Besuked & Assumanct \\
\hline 205 & Keleazinaz Spurepan & Assumence \\
\hline
\end{tabular}

\section{KuadranII}

Kuadran II adalah "Pertahankan Prestasi" dimana pada kuadran ini memiliki tingkat skor yang paling tinggi baik dari segi tingkat kepentingan pelanggan dan tingkat kinerjanya, sehingga atribut yang berada pada kuadran II dapat dikatakan aman dan harus dipertahankan kinerjanya. Atribut yang di plotting ke dalam kuadran ini antara lain atribut R2,RE1,AR2,AR3,R 3,RE2,T4,(lebih jelasnya pada table 5.2 .2 berikut )

\begin{tabular}{|c|c|c|}
\hline KuADGaN2 & ATMAST & ONons: \\
\hline$\$ 2$ & Hasil Service Das Penzecedan Yang Sevai & scaauTr \\
\hline REI & Kocrpetun Kaser Dalam Proses Penbayann & Eeponsive \\
\hline ANO & Keramulan Dan Kesopaman Petugas Bengiel & ASSURANCE \\
\hline ans & Petugas Bengked Mendengr Permintsan Pelantzan & ASSURANGE \\
\hline 13 & $\begin{array}{l}\text { Juminh Mokanik Sebanding Dencue Kendaran Yane } \\
\text { Disevis }\end{array}$ & eszanur \\
\hline 262 & 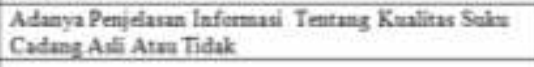 & RESPONSENE \\
\hline $\mathrm{Ta}$ & Iessedia Minuman Gratis & TANGIHEA \\
\hline
\end{tabular}

\section{KuadranIII}

Kuadran III adalah "Prioritas Rendah", dimana atribut ini dianggap kurang penting pengaruhnya bagi pelanggan dan pada kenyataannya kinerjanya tidak terlalu istimewa. Bagi pihak bengkel sebaiknya perlu dipertimbangkan lagi pada atribut ini karena atribut yang masuk pada kuadran ini dianggap kurang penting dan kurang memuaskan bagi pelanggan Bengkel Nader Jaya Motor. Atribut 
yang di plotting ke dalam kuadran ini antara lain atribut pertanyaan atribut E1 ( lebih jelasnya pada table 5.2 .3 berikut )

Tabel 5. 3Atribut-Atribut Kuadran III

\begin{tabular}{|l|l|l|}
\hline KuAduan 3 & Atriaut & OMK \\
\hline a & $\begin{array}{l}\text { Penjelasan Staf Mengenai Perbaikan } \\
\text { Biaya, Wuktu }\end{array}$ & RMP. \\
\hline
\end{tabular}

\section{KuadranIV}

Kuadran IV adalah "Berlebihan", ini menunjukkan bahwa atribut pada kuadran ini dinilai memiliki tingkat harapan yang rendah namun tingkat kinerja yang diberikan tinggi. Dianggap kurang penting tetapi pelayanan yang diberikan sangat memuaskan pelanggan Bengkel Nader Jaya Motor. Atribut yang di plotting kuadran ini antara lain atribut pertanyaan E2,E3 ( lebih jelasnya pada table 5.3.4 berikut )

Tabel5.4Atribut-Atribut Kuadran IV

\begin{tabular}{|c|c|c|}
\hline KUADRANA & ATRIBUT & DEVENSI \\
\hline E2 & $\begin{array}{l}\text { Kemampuan Staf Dalam Belkomumilasi Dengan } \\
\text { Pelanggan }\end{array}$ & EMPATY \\
\hline B3 & Kemudahan Pendaftaran Ketika Servis & EVPATY \\
\hline
\end{tabular}

\section{Analisis Customer Satisfaction Indeks (CSI)}

Berdasarkan analisis kepuasan konsumen secara keseluruhan dilakukan dengan menghitung nilai Customer Satisfaction Index (CSI). Nilai CSI diperoleh dengan membagi Weighted Average (Penjumlahan seluruh Weighted Score) dengan skala maksimum (skala lima) yang digunakan dalam penelitian ini. Skala kepuasan pelanggan yang umum dipakai dalam interprestasi indeks adalah skala 0 sampai skala 1. Berdasarkan dari hitungan indeks kepuasan pelanggan, nilai CSI Bengkel Nader Jaya Motor mendapatkan skor sebesar 69,445 \% yang berada pada rentang 66 - 80 kepuasan pelanggan Bengkel Nader Jaya Motor secara keseluruhan yang dilihat berdasarkan kepuasan dan kepentingan atirbut-atribut berada pada kriteria "puas".

Meskipun demikian dengan berkembangnya banyaknya jasa bengkel, maka dari itu dari pihak Bengkel Nader Jaya Motor harus bisa ditingkatkan lagi kinerjanya pada taraf sangat puas yang diindikasikan dengan nilai CSI yang mendekati angka 100\% itu akan jauh lebih baik, dimana pelanggan benar-benar merasakan kinerja atribut-atribut dari Bengkel Nader Jaya Motor sama dengan tingkat kepentingan yang merekatetapkan. Akan tetapi Bengkel Nader Jaya Motor harus tetap meningkatkan kualitas pelayanan khususnya pada atribut yang kinerjanya kurang memuaskan.

\section{Interprestasi Hasil}

Dalam penelitian ini bahwa ada beberapa atribut yang perlu di perbaiki ole bengkel tesebut karena mempengaruhi kualitas pealyanan bengkel yaitu pada kuadran I untuk kuadran I Prioritas Utama dimana atributatribut yang berada di dalam kuadran ini harus mendapatkan perhatian lebih atau harus diperbaiki.

Hal tersebut menunjukkan bahwa pelanggan merasakan ketidakpuasan terhadap kinerja bengkel atribut atau dimensi layanan yang telah diberikan, sehingga perlu adanya perbaikan pada atribut tersebut dan perlu diprioritaskan. Atribut-atribut tersebut antara lain Bengkel Bertanggung Jawab Penu Hasil Service,Kualitas Servis Yang Diberikan 
kurang, Adanya Penjelasan Informasi Tentang Kualitas Suku Cadang Asli Atau Tidak, Kebersihan,Kenyamanan Fasilitas-Fasilitas Yang Diberikan Oleh Bengkel,Area Parkir Yang Luas Dan Bersih,Kelengkapan Peralatan Begkel,Ketepatan Waktu Pada Saat Pengerjaan Service Dengan Waktu Selesai Pengerjaan Yang Diberikan Mekanik,Jam Keja Bengkel,Kelengkapan Sparepart .

Maka pihak bengkel harus melakukan perbaikan dengan meningkatkan kualitas pelayanan kinerja bengkel seperti melakuakan perbaikan pada atribut kuadran 1 yaitu pada atribut bengkel bertanggung jawab penu hasil sevis atribut tersebut kinerjanya masi kurang seharusnya pihak bengkel menambahkan masa garansi perbaikan motor dalam waktu 7 hari atau lebih, atribut selanjutnya yaitu meningkatkan kualitas servis perbaikan yang diberikan dengan memberikan pealatihan atau pengatahuan khusus kepada mekanik karena setiap tahunya sepeda motor selalu berganti, atribut selanjutna yaitu pegawai menjelaskan secara detail suku cadang mana yang asli atau tidaknya, kebersihan dan fasilitas yang masi kurang pihak bengkel harus meningkatkan kebersihan dan menambahkan fasilitas umum lainya seperti toilet dan kipas angin, atribut selanjutnya area parkir luas tapi kinerja bengkel masi belum puas menurut pelangan sebaiknya pihak bengkel menambah area parkir sehingga para pelanggan tidak parkir di bahu jalan, kelengkaan peralatan bengkel pihak bengkel menambah peralatan bengkel supaya mekanik melakukan perkerjaan cepat, tepat waktu dan pelanggan tidak menunggu lama, dan bengkel harus menambah kelengkapan stok sparepart sehingga pelanggan dalam mengganti sparepart tidak menunggu lama dalam pengerjaannya, pelanggan merasa puas dalam kinerja bengkel dan mengurangi rasa kecewa daripelanggan.

Dalam nilaicustomer saticfaction index (CSI) sebesar 69,445\% berartiberarti masih ada 30,55\% konsumenyang belum mampu dipuaskan sepenuhnya oleh bengkel tersebut. Meskipun demikian dengan berkembangnya banyaknya jasa bengkel, maka dari itu dari pihak Bengkel Nader Jaya Motor harus bisa ditingkatkan lagi kinerjanya pada taraf sangat puas yang diindikasikan dengan nilai CSI yang mendekati angka 100\% itu akan jauh lebih baik, dimana pelanggan benar-benar merasakan kinerja atribut-atribut dari Bengkel Nader Jaya Motor sama dengan tingkat kepentingan yang merekatetapkan. Akan tetapi Bengkel Nader Jaya Motor harus tetap meningkatkan kualitas pelayanan khususnya pada atribut yang kinerjanya kurang memuaskan. 


\section{KESIMPULAN}

Berdasarkan pada hasil penelitian yang telah dilakukan pada Bengkel Nader Jaya Motor, maka didapatkan kesimpulan sebagai berikut :

1.Nilai CSI tingkat kepuasan pelanggan terhadap pelayanan Bengkel Nader Jaya Motor adalah 69,445\% artinya pelanggan merasa "puas" atas kinerja pelayanan dari Bengkel Nader Jaya Motor.

2.Untuk peningkatan kualitas pelayanan Bengkel Nader Jaya Motor yang lebih optimal, pihak Bengkel Nader Jaya Motor harus segera memperbaiki atribut-atribut pada atribut kuadaran I seperti bengkel bertanggung jawab penuh hasil servis,Kualitas Servis Yang Diberikan bengkel Adanya Penjelasan Informasi Tentang Kualitas Suku Cadang Asli Atau Tidak, Kebersihan Kenyamanan Fasilitas-Fasilitas Yang Diberikan Oleh Bengkel, Area Parkir Yang Luas Dan Bersih kelengkapan Peralatan Begkel, Ketepatan Waktu Pada Saat Pengerjaan Yang Diberikan Mekanik,Jam Keja Bengkel ,Kelengkapan Sparepart

3. Usulan yang diperlukan oleh Bengkel NADER JAYA MOTOR adalah:

- seharusnya pihak bengkel bekerja sama dengan dealer resmi supaya suku cadang lengkap dan tidak menunggu lama.

- Pihak bengkel menambah kelengkapan peralatan mekanik .

- Pihak bengkel membuat keputusan jam kerja opreasional dalam melakukan pengerjaan.

\section{Saran}

Peneliti dapat beberapa saran yang diharapkan berguna untuk bengkel nader jaya motor atau pihak- pihak yang bersangkutan dalam hal ini. Adapun saran-saran sebagai berikut:

1. Perbaikan harus dipantau dan dievaluasi agar kepuasan pelanggan bengkel Bengkel Nader Jaya Motor benar-benarterpenuhi.

2. Tetap mempertahankan atribut-atribut yang dianggap sudah memuaskan pelanggan sehingga Bengkel Nader Jaya Motor akan lebih fokus untuk meningkatkan pelayanan yang dianggap kurang.

\section{Daftar Pustaka}

Aera Santiana, H. (2018). Sistem Informasi Pelayanan Jasa Service Pada Bengkel Cipta Prima Motor Cibitung. INFORMATION SYSTEM FOR EDUCATORS AND

PROFESSIONALS, Vol.2, No., 201214.

Aviliani dan Wilfridus, 2002 Membangun Kepuasan Melalui Kualitas Layanan 79. Amerika: America Marketing Association (diakses pada selasa, 3 Oktober 2015).

Baloglu, Seyhmus, 2002 Dimensions Of Customer Loyalty, Bumi Aksara, Jakarta

Gazpersz, Vincent. 1997. Manajemen Kualitas Penerapan Konse-konsep Penerapan Kualitas Dalam Manajemen Bisnis Total. Jakarta: Gramedia Pustaka Utama.

Ghozali, Imam. 2006. Aplikasi Analisis Multivariate Dengan Program SPSS, Cetakan Keempat. Semarang: Badan Penerbit UNDIP

Parasuraman, A., Zeithmal, V.A. and Berry, L.L. (1988). SERVQUAL: A Multiple 
Item Scale for Measuring Consumer

Perceptions of Service Quality. Journal of Retailing, 64(1), 1240.

Sugiyono, 2010. Statistik Untuk Penelitian, Bandung: Alfa Beta

Supranto, J. 2006. Pengukuran Tingkat Kepuasan Pelanggan Untuk Menaikan Pangsa Pasar. Jakarta: Rineka Cipta

Tjiptono, F., dan Gregorius, C. 2005. Service Quality dan Satisfaction. Yogyakarta: Andi Yogyakarta
Tse dan Wilson 2000 Visi Kualitas

Jasa, Gramedia, Jakarta

Yamit, Z. 2005. Manajemen Kualitas Produk dan Jasa. Jakarta: Ekonisia Zeithaml, Valene A. Berry, Leonard L. and Parasuraman, A. (1996), "The Behavioral Consequences of Service Quality", Journal of Marketing, Vol. 60, April, pp 31- 46 